\title{
Evaluation of thinking style among medical and dental students of Ilam University of Medical Sciences in academic year of 2016-2017
}

\author{
Sareh Shakerian Rostami ${ }^{1}$, Ali Sohrabnejad ${ }^{1 *}$, Alireza Mirzaei ${ }^{2}$
}

1. School of Medical Education, Shahid Behesti University of Medical Sciences, Tehran, Iran

2. The Center for Research and Development in Medical Education, Ilam University of Medical Sciences, Ilam, Iran

*Corresponding author:Tel: +989188430567 Fax: +98 -

Address: School of Medical Education, Shahid Behesti University of Medical Sciences, Tehran, Iran

E-mail: asnsohrabi@gmail.com

Received; 2017/10/25 revised; 2017/11/27 accepted; 2017/12/27

\section{Abstract}

Introduction: Education and research are two thinking based processes. Nowadays, the main function of educational institutions is evaluated by thinking. This study aimed to determine the dominant thinking styles among medical and dental students of Ilam University of Medical Sciences (IUMS).

Materials and methods: This cross-sectional study was conducted on all medical and dental students of IUMS in the academic year of 2016-2017. Data was collected by Sternberg's standard thinking style inventory and a demographic data questionnaire. Data analysis was carried out with the software SPSS 20 using descriptive statistical analysis methods and t-test. Results: In total, 497 students of IUMS participated in the study. Among whom 395 (79.5\%) were medicals students and $102(20.5 \%)$ were dental students. The findings showed significant differences between the legislative and executive thinking styles of medical and dental students $(\mathrm{P}=0.042$ and $\mathrm{P}=0.024$ respectively), more specifically, the mean score of legislative thinking style was found to be higher among dental students than that of medical students, and the opposite relation was found in the mean scores of executive thinking style. Comparison of mean scores of thinking style dimensions between medical and dental students showed significant differences in some but not all dimensions.

Conclusion: Considering the differences found in thinking styles of medical and dental students and their effects in emergence of unique behavioral and decision-making characteristics in medical and dental students, educational planners and professors should attempt to adjust their teaching methods and professional approach according to students individual features in terms of thinking style and preferences so as to foster the growth and flourish of their thinking, academic, and clinical capabilities. The results of the study showed significant differences between the legislative and executive thinking styles of medical and dental students, also regarding the different dimensions of thinking styles of medical and dental students, some significant differences in some but not all dimensions were reported.

Keywords: Thinking, Thinking style, Medical and dental students

\section{Introduction}

Student's thinking and cognitive styles and their relation with academic performance is a well-investigated avenue of educational research. The importance of this subject stems from direct effect of students' thinking style on how they decide, plan,

Copyright (C) 2018 Journal of Basic Research in Medical Science. This is an open access article distributed under the terms of the Creative Commons Attribution 4.0 International License (https://creativecommons.org/licenses/by/4.0/) which permits copy and redistribute the material, in any medium or format, provided the original work is properly cited. 
behave, and deal with different challenges of learning environment, and the consequent effects on their learning performance (1).

Despite the wide range of learning and education models, all models are consistent considering how information and experiences are perceived, organized, and analyzed via individuals. This means that different people have different views on the world, and interests and preferences regarding thinking and learning may vary from one person to another (2). Thinking style characterizes the way people learn, think, and perceive, not their ability to do so. In other words, it is a means to identify and describe how people are different in their perceptions, in their approach to pursuit knowledge, in the way they produce and shape ideas, and in their behavior (3).

Discovering one's thinking style can help a person identify his/her strengths and weaknesses and understand how he/she can improve his/her decision-making and problem-solving strategies. Typically, people are not conscious of how their thinking style affects their performance, but an educated and conscious effort to determine one's thinking style and its difference from others can help the person utilize this effect more effectively. Research has shown that educating students on their thinking styles improves their academic performance, and that the first step before guiding students in the right direction is to identify their potential and actual thinking styles (2). Therefore, evaluation of students' thinking styles is an essential prerequisite for the improvement of learning processes and this study is an effort toward this goal.

Sternberg's theory of mental selfgovernment proposes 13 thinking styles categorized into 5 dimensions: functions, forms, levels, scope, and leanings. There thinking styles are divided into three different styles including; legislative, executive, and judicial. Those individuals with legislative thinking style are able to create, invent, and design; the individuals with executive thinking style prefer to be told what to do; and those individuals with judicial thinking style like to evaluate and judge methods and ideas. In the leanings dimension, there are two thinking styles: liberal and conservative. People with liberal thinking style tend to try new ways of doing things and to challenge customs and customary ways, whereas people with conservative thinking style tend to work with firmly established procedures and in what they describe as proper way $(4,5)$.

The effects of thinking style in different fields are extensively researched. For example, Zhang (2006) has reported that educating students from Hong Kong about thinking styles improved their academic performance (6). In another study, Qing and Chuan (2004) have found a significant relationship between creativity and critical thinking with thinking styles (7). A similar research by Emamipoor and Saif (2003) has shown a relationship between thinking styles and academic performance of Iranian students (8).

Identification of dominant thinking and learning styles among students allow the teaching staff and authorities in charge of education development to make appropriate plans and take necessary measures to improve the quality of education. In view of the lack of such data on the students of Ilam University of Medical Sciences (IUMS), this study was carried out to identify dominant thinking styles of medical and dental students of this university.

\section{Materials and methods}

In this cross-sectional study, the population consisted of all medical $(n=477)$ and dental $(n=118)$ students of IUMS in the academic year of 2016-2017. The inclusion criterion was participation in at least one course in the autumn semester of this academic year. Considering the accessibility of population, the study was carried out by census survey instead of sampling. Thus, the total size of surveyed population was $n=595$ consisting of 477 medical students and 118 dentals students, but given the $83 \%$ response rate of 
medical students and $87 \%$ response rate of dental students, the final group sizes were 395 and 102 respectively (497 in total).

Data was collected by a standard demographic questionnaire and a thinking style assessment inventory devised based on Sternberg's theory of mental selfgovernment.

Face and content validity of the questionnaires were verified by collective judgment of university professors with expertise in the field of medical education. Reliability of questionnaires was evaluated by test-retest method. For this purpose, questionnaires were distributed among and collected from 5\% of population; this process was repeated 10 days later (with the same people). Finally, test-retest reliability of thinking styles inventory was evaluated by Spearman's correlation and Cronbach's alpha.

To collect the data, questionnaires were distributed among the population by the researcher and a trained investigator. By courtesy of lecturers and university administration, brief sessions were held in the classrooms at the end of lessons. In every session, the purpose of the study was explained and students voluntarily filled the questionnaires; the completed questionnaires were collected.

\section{Statistical analysis}

Data analysis was performed based on the frequency distribution of central tendency and dispersion. To do so the SPSS 20 software, using descriptive statistical analysis methods and t-test, was used. The mean scores of thinking style of medical and dental students were compared by the independent $\mathrm{t}$-test with maximum error of $5 \%$.

\section{Results}

In total, 497 students participated in the study. Of these, 209 (42.1\%) were male and 288 (57.9\%) were female; and 395 were medicals students (79.5\%) and $102(20.5 \%)$ were dental students. Table 1 presents the obtained descriptive statistics in relation with the prevalence of thinking styles among medical and dental students at IUMS.

Table 2. Prevalence of thinking styles among medical and dental students.

\begin{tabular}{lccc}
\hline Dimensions & Thinking style & Medical students & Dental students \\
\hline Functions & Legislative & $24.74 \pm 4.06$ & $25.78 \pm 4.22$ \\
& Executive & $28.93 \pm 4.01$ & $27.68 \pm 4.01$ \\
Levels & Judicial & $28.57 \pm 5.27$ & $28.37 \pm 4.35$ \\
& Global & $28.06 \pm 5.46$ & $26.75 \pm 4.77$ \\
Forms & Local & $26.61 \pm 4.75$ & $28.00 \pm 4.91$ \\
& Monarchic & $27.26 \pm 4.75$ & $27.48 \pm 4.54$ \\
& Oligarchic & $28.84 \pm 5.34$ & $28.66 \pm 4.82$ \\
& Hierarchic & $24.91 \pm 4.92$ & $26.78 \pm 3.91$ \\
Scope & Anarchic & $26.30 \pm 5.34$ & $26.63 \pm 3.75$ \\
& Internal & $26.39 \pm 5.23$ & $27.22 \pm 4.09$ \\
Leanings & External & $27.85 \pm 5.96$ & $27.68 \pm 4.79$ \\
& Liberal & $28.24 \pm 5.21$ & $27.63 \pm 4.62$ \\
& Conservative & $26.23 \pm 5.34$ & $28.22 \pm 5.61$ \\
\hline
\end{tabular}

Data are shown as mean \pm standard deviation.

As shown in Table 1, in the dimension of functions, the highest and lowest scores (mean) of medical students were in executive (28.93) and legislative (24.74) thinking styles respectively; but for dental students, the highest and lowest scores (mean) were observed, respectively, in judicial (28.37) and legislative (25.78) thinking styles. The results obtained for the dimension of levels showed that among 
medical students, global thinking style (28.06) had a higher mean score than local thinking style (26.61), but among dental students, the mean score of local thinking style (28.00) was higher than that of global (26.75).

In the dimension of forms, the highest and lowest mean scores of medical students were observed in oligarchic (28.84) and hierarchic (24.91) thinking styles respectively. A similar trend was also observed among dental students, as their highest and lowest mean scores were related to oligarchic (28.66) and hierarchic (26.78) thinking styles as well.

Regarding the dimension of scope, for medical students, the mean score of external thinking style (27.85) was found to be slightly higher than that of internal thinking style (26.39), but the opposite relation was observed in mean scores of internal (27.68) and external (27.22) thinking styles of dental students.

Considering the dimension of leanings, the mean score of liberal thinking style (28.24) of medical students was higher than their mean score in conservative thinking style (24.23), but for dental students, the mean score of liberal thinking style (28.22) was found to be higher than that of conservative thinking style (27.63).

\section{Discussion}

The findings of this study are consistent with the results of Ahanchian et al., who have reported the dominance of judicial thinking style in nursing students of Mashhad University of Medical Sciences (9). A study by Ford et al. on the thinking styles of students of an English college and also Yale University demonstrated that male students are more intended in legislative thinking in contrast of female students who are more interested in exhibit executive style (9). Sarvghad et al. have reported that thinking styles with lowest and highest mean scores among high school seniors are conservative and legislator styles respectively (10). A study by Sherif et al., on the students of Islamic Azad
University of Roudehen has reported the dominance of legislator thinking style among students (11). In terms of Levels, global thinking style was found to be more prevalent than local thinking style among medical students; but among dental students, local thinking style was more prevalent than global thinking style. The latter finding is consistent with the result of a study by Shokri et al., which has reported a higher mean score for local thinking style than global thinking style (5). In the case of medical students, the difference of our results from those of previous studies may be due to the differences in the subjects, disciplines, and their attributes. Our finding with regard to the dimension of Forms showed that thinking styles with highest and lowest mean scores among medical and dental students are oligarchic and hierarchic. These findings are in consistent with the findings of Selk and Atashpour, who have reported the dominance of hierarchic thinking style among surveyed group (managers and supervisors of Assaluyeh industrial complex) (12) and also Ahanchian et al., who have reported the dominance of anarchic thinking style among students of Mashhad University of Medical Sciences (9). The difference of our results from those of aforementioned studies can likely be attributed to the differences in the studied populations. In the dimension of Scope, medical students had a higher mean score for external thinking style than for internal, but dental students had a higher mean score for internal thinking style than for external. These results are in consistent with the findings of Selk and Atashpour (12). In the dimension of leanings, medical students had a higher mean score for liberal thinking style than for conservative thinking style. Considering this fact, a study by Safari et al. on the students of Kermanshah University of Medical Sciences has shown a significant positive relationship between liberal thinking style and academic performance (13). Our result also showed that surveyed dental students had a higher 
mean score in conservative thinking style than in liberal. So, Ahanchian et al., have reported the dominance of liberal thinking style in nursing students of Mashhad University of Medical Sciences (9), and Keshtkaran et al., who have investigated the relationship between thinking styles and learning styles among students of Shiraz University of Medical Sciences by assuming a combined style called liberalconservative have reported that this particular style has a direct relationship with learning style (2).

\section{Limitations}

To avoid costly and time consuming implementation, the research was conducted by convenience sampling with entire attention concentrated on Ilam School of medicine and dentistry. Thus, the results are subject to population-based limitations which restrict their generalizability. Another limitation of this study is the focus on a limited number of thinking style constructs, that is to avoid the breadth of questions that otherwise need to be included in the questionnaire and may undermine the students willingness to participate. Also, since the data was in form of self-reports collected by questionnaires, it is reasonable to recognize that cultural, social, and psychological background of respondents may have affected the

\section{References}

1. Simin S, Azizollah A, Nasrin $M$. Progression trend of critical thinking among nursing students in Iran. Int $\mathbf{J}$ Med Res Health Sci. 2017;6(1): 98-102.

2. Keshtkaran A, Sadeghifar J. [A study on the relationship between thinking styles and preference learning methods among students of Shiraz University of Medical Sciences]. J Med Educ Dev 2013, 6(10): 50-5. (Persian)

3. Seif A. [Educational psychology]. Tehran. Agah Publications. 2006. (Persian)

4. Ko S. Do thinking styles of responses. The authors recommend another study to be conducted on a broader scale with random sampling of medical and dental students and use of other data collection approaches such as behavioral measurement.

\section{Conclusion}

Based on the results of the study it can be concluded that there are some significant differences between the legislative and executive thinking styles of medical and dental students, considering the different dimensions of thinking styles among the two groups of students, some significant differences in some but not all dimensions were reported. Since reliance on each thinking style leads to emergence of unique behavioral and decision-making characteristics in medical and dental students, it is suggested that educational planners and professors attempt to adjust their teaching methods and professional approach according to students individual features in terms of thinking style and preferences so as to foster the growth and flourish of their thinking, academic, and clinical capabilities.

\section{Acknowledgments}

This study was supported by Shahid Behesti University of Medical Sciences.

entrepreneurs matter in innovation? J Glob Busin Technol. 2008; 4(2): 24-33.

5. Shokri O, Kadivar P, Farzad V E, Daneshvarpour Z. Thinking styles and learning approaches in relation to students' academic achievement. Advance Cognit Sci. 2006; 8 (2) :44-52.

6. Goodbrand A. The art of thinking: the classic guide to increasing brain Power Berkley; Reprint edition (February 5, 2002).

7. Zhang LF. Revisiting the predictive power of thinking styles for academic performance. J Psychol. 2004; 
138(4):351-70.

doi: 10.3200/JRLP.138.4.351-370

8. Mahboubeh H, Leila Z, Akram M. Relationship between types of thinking styles and academic adjustment with academic achievement among high school students. Social Sci. 2016;11(9): 2241-9. doi: 10.3923/sscience.2016.2241.2249

9. Ahanchian M, Hassanian Z. Relationship between thinking and problem solving styles in nursing students. J Nurs Educ. 2013; 2(3): 3848.

10. Sarvghad S, Rezaei A, Masoomi F. Relationship of thinking styles with self-efficacy among male and female senior high school students in Shiraz.
Sociol Women. 2011; 1(4): 135-56.

11. Ghazivakili Z, Norouzi Nia R, Panahi F, Karimi M, Gholsorkhi H, Ahmadi Z. The role of critical thinking skills and learning styles of university students in their academic performance. J Adv Med Educ Prof. 2014;2(3):95-102.

12. Hendel T, Fish M, Galon V. Leadership style and choice of strategy in conflict management among Israeli nurse managers in general hospitals. J Nurs Manag. 2005;13(2):137-46.

13. Yahya S, Nasrin Y, Raoshan A. [Assessing dimensions of students' thinking style and its relationship with academic performance in Kermanshah University of medical sciences]. J Med Educ Dev. 2015, 8(17): 38-46. (Persian) 